\title{
Integration of spatial and temporal data for the definition of different landslide hazard scenarios in the area north of Lisbon (Portugal)
}

\author{
J. L. Zêzere, E. Reis, R. Garcia, S. Oliveira, M. L. Rodrigues, G. Vieira, and A. B. Ferreira \\ Centro de Estudos Geográficos, Faculdade de Letras, Cidade Universitária, 1600-214 Lisboa, Portugal \\ Received: 2 September 2003 - Revised: 27 November 2003 - Accepted: 5 January 2004 - Published: 9 March 2004 \\ Part of Special Issue "Landslide and flood hazards assessment"
}

\begin{abstract}
A general methodology for the probabilistic evaluation of landslide hazard is applied, taking in account both the landslide susceptibility and the instability triggering factors, mainly rainfall. The method is applied in the FanhõesTrancão test site (north of Lisbon, Portugal) where 100 shallow translational slides were mapped and integrated into a GIS database.
\end{abstract}

For the landslide susceptibility assessment it is assumed that future landslides can be predicted by statistical relationships between past landslides and the spatial data set of the predisposing factors (slope angle, slope aspect, transversal slope profile, lithology, superficial deposits, geomorphology, and land use). Susceptibility is evaluated using algorithms based on statistical/probabilistic analysis (Bayesian model) over unique-condition terrain units in a raster basis. The landslide susceptibility map is prepared by sorting all pixels according to the pixel susceptibility value in descending order.

In order to validate the results of the susceptibility analysis, the landslide data set is divided in two parts, using a temporal criterion. The first subset is used for obtaining a prediction image and the second subset is compared with the prediction results for validation. The obtained prediction-rate curve is used for the quantitative interpretation of the initial susceptibility map.

Landslides in the study area are triggered by rainfall. The integration of triggering information in hazard assessment includes (i) the definition of thresholds of rainfall (quantityduration) responsible for past landslide events; (ii) the calculation of the relevant return periods; (iii) the assumption that the same rainfall patterns (quantity/duration) which produced slope instability in the past will produce the same effects in the future (i.e. same types of landslides and same total affected area).

The landslide hazard is present as the probability of each pixel to be affected by a slope movement, and results from

Correspondence to: J. L. Zêzere

(jlzezere@sapo.pt) the coupling between the susceptibility map, the predictionrate curve, and the return periods of critical rainfall events, on a scenario basis.

Using this methodology, different hazard scenarios were assessed, corresponding to different rain paths with different return periods.

\section{Introduction}

Varnes et al. (1984) proposed the most widely adopted definition for landslide hazard as "the probability of occurrence of a potentially damaging phenomenon (landslide) within a given area and in a given period of time". As Guzzetti et al. (1999) and Aleotti and Choudhury (1999) pointed out, this definition incorporates the concepts of spatial location ("where"?), time recurrence ("when"?) and magnitude ("how powerful"?) as crucial elements in the prediction of future landslide behaviour.

The definition of landslide prone zones at a regional scale has been attempted in the last few decades using direct (geomorphological) and indirect (quantitative and semiquantitative) methods (Hansen, 1984; Hutchinson, 1995; Soeters and Van Westen, 1996; Carrara et al., 1998; Aleotti and Choudhury, 1999). Both approaches are based on the principle that future landslides are more likely to occur under the same conditions that led to past slope instability. Therefore, the spatial component of landslide hazard may be assessed by combining the spatial distribution of past slope movements with the spatial patterns of the relevant predisposing factors of slope instability (Carrara et al., 1998). The obtained landslide susceptibility maps provide a classification of the study area only in terms of "spatial probability". Furthermore, these susceptibility maps need to be validated in order to evaluate their predictive power with respect to future slope movements. As Guzzetti et al. (1999) and Chung and Fabbri (in press) pointed out, strictly speaking, validation of the prediction of future landslides is not possible. Despite this constraint, some attempts have been carried out to 


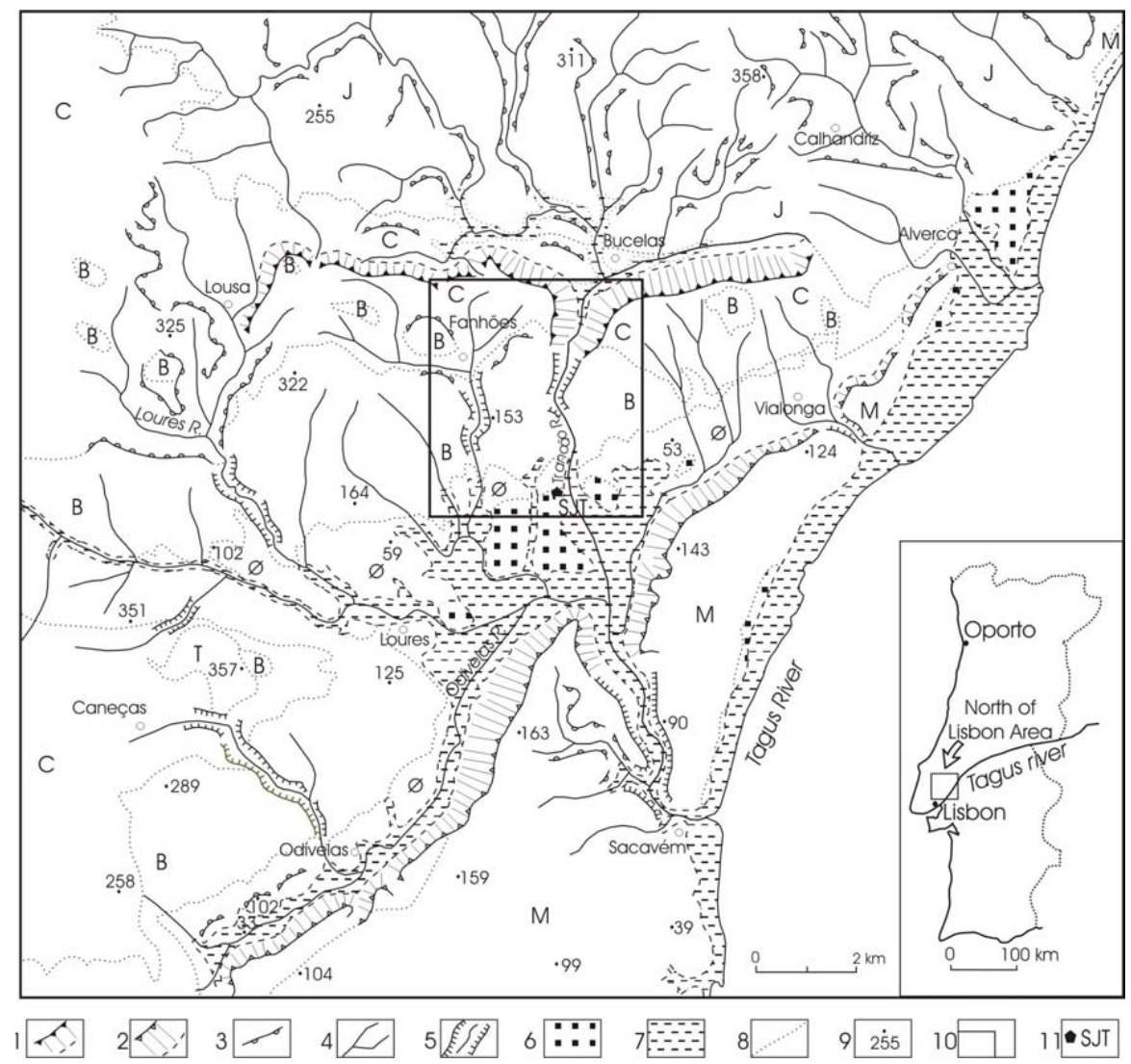

Fig. 1. Schematic geomorphological map of the Area North of Lisbon. 1. front of Lousa-Bucelas cuesta; 2. front of Odivelas-Vialonga cuesta; 3 . other cliffs; 4. river; 5. gorge; 6. fluvial terrace; 7. alluvial plain; 8. geological boundary; 9. elevation in meters; 10. Fanhões-trancão test site; 11. location of S. Julião do Tojal raingauge.

J. Jurassic rocks (clays, marls, limestones, sandstones); C. Cretaceous sedimentary rocks (sandstones, marls and limestones); B. Upper Cretaceous Volcanic Complex of Lisbon; $\varnothing$. Paleogene detrital complex; M. Miocene (sandtones, limestones and clays). measure the reliability of landslide susceptibility predictions (e.g. Yin and Yan, 1988; Carrara et al., 1995; Irigaray et al., 1996; Zêzere, 2002). However, such works did not provide a validation of prediction but of "success-rate", because the same landslide data set was used to construct the prediction analysis and to validate the susceptibility models. Chung and Fabbri (in press) discussed how to provide empirical measures of significance of the prediction results through spatial/time partitioning of the spatial landslide databases.

By definition, a hazard map should include an evaluation of the probability of occurrence of new landslides, thus implying the consideration of a time dimension. Unfortunately, this is not the case of most published regional landslide "hazard" assessments, which generally only provide a ranking of terrain units in terms of susceptibility, not considering the temporal component of the hazard. In general this limitation is due to the fact that for a complete hazard assessment there are a lot of obstacles to overcome including: (i) the discontinuous nature in space and time of slope failures; (ii) the difficulty of identifying the causes, the triggering factors and cause-effect relationship and (iii) the lack of a complete historical data concerning the frequency of landslides. However in the case of rainfall induced landslides, as those discussed in this paper, the statistical analysis of rainfall data may enable both the definition of the triggering threshold and calculation of the recurrence interval (Aleotti and Choudhury, 1999).
The main objective of this study developed on a test site in the area north of Lisbon is to apply a comprehensive methodology to assess landslide hazard integrating spatial and temporal data. Landslide susceptibility is evaluated using algorithms based on statistical/probabilistic analysis. A crossvalidation procedure is applied to validate the landslide prediction model, using a spatial/temporal partition of the distribution of the past slope movements. Finally, different probabilistic hazard scenarios are defined through integration of landslide frequency information.

\section{Study area}

The area North of Lisbon is part of the Portuguese MesoCenozoic sedimentary basin and is located close to the tectonic contact between this morphostructural unit and the Tagus alluvial plain (Fig. 1). This area has been affected by a positive tectonic deformation since the Tortonian (6 M years), which explains the vigorous downcutting of the rivers responsible for the steep slopes, although the maximum height of the study area does not surpass $350 \mathrm{~m}$. The geological structure forms a monocline with the layers dipping south and southeast towards the Tagus estuary. The alternation of rocks of different hardness, permeability and plasticity, together with the monocline setting allowed the development of cuestas (Lousa-Bucelas and 


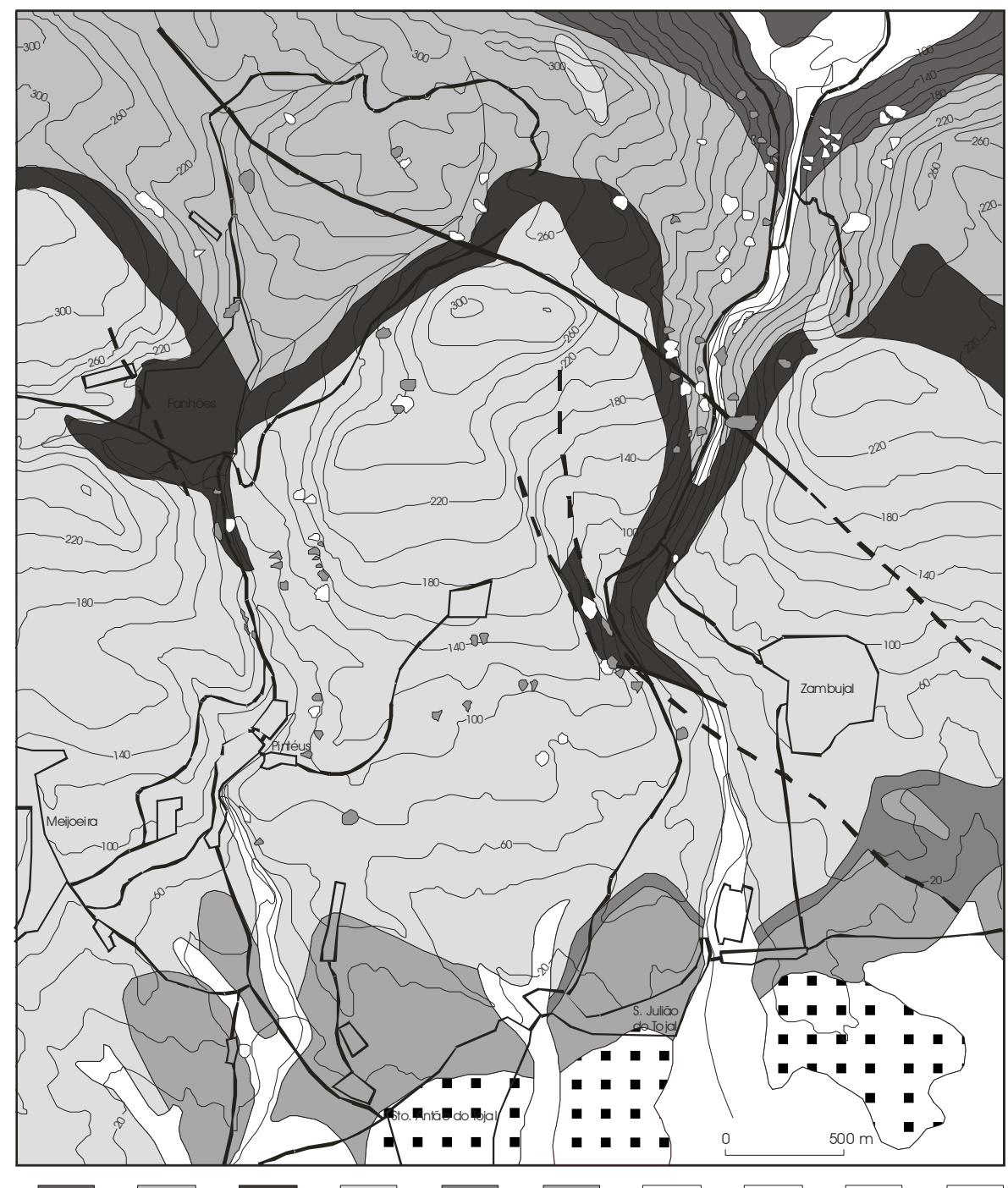

1
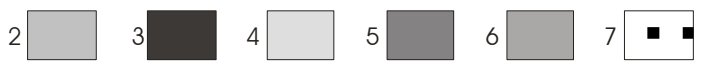

$8 \square$

$9 \bigcirc 10$

Fig. 2. Geological map of the FanhõesTrancão test site and spatial distribution of shallow translational slides.

1. Upper Barremian - Aptian sandstones (LU1); 2. Albian - Middle Cenomanian marls and marly limestones (LU2); 3. Upper Cenomanian limestones (LU3); 4. Upper Cretaceous Volcanic Complex of Lisbon (LU4); 5. Paleogene lacustrine limestones (LU5); 6. Paleogene conglomerates and sandstones (LU6); 7. Quaternary terraces; 8. Alluvial plain; 9. Fault, uncertain (dashed); 10. Shallow translational slides (white, age $\leq 1979$, grey, age $>1979$ ).

Odivelas-Vialonga) and nearly closed basins (e.g. Loures basin) during Quaternary.

The test site of Fanhões - Trancão is a $20 \mathrm{~km}^{2}$ sub-area located in the dip slope of the Lousa-Bucelas cuesta (Fig. 1). This substructural slope is characterized by a general concordance between topography and the dip of strata $\left(12^{\circ}\right)$ towards the south and southeast. The test site includes two main cataclinal valleys: the valley of Fanhões river, at the west side, and the deep valley of Trancão river, at the east side, which profoundly cuts the cuesta relief.

From the lithological point of view, six units can be distinguished (Fig. 2, Table 1), apart from Quaternary terraces on the north section of the Loures basin, and alluvial deposits which partly fill the main valleys. The sandstones of upper Barremian-Aptian (Lithological Unit 1, LU1) only appear in the north sector of the Trancão river valley. Lithological Unit 2 (LU2, Albian-middle Cenomanian age) is a heterogeneous formation mainly formed by marls, with marly limestone and limestone intercalations. In the Trancão valley, this lithological unit is usually covered by slope deposits with a thickness generally higher than $0.5 \mathrm{~m}$. The compact limestones of upper Cenomanian age (Lithological Unit 3, LU3), although limited in area, are clearly perceptible in the landscape, appearing as important rock walls on the middle part of the Trancão valley as well as on the left slope of the main tributary of the Fanhões river. The Volcanic Complex of Lisbon (Lithological Unit 4, LU4, Upper Cretaceous age) lies above the Cenomanian limestones in more than half of the test site. This volcanic formation is very heterogeneous including compact and weathered basalts, and volcanic tuffs. The Paleogene formations can be found to the south of the eruptive outcrops. They include lacustrine limestones (Lithological Unit 5, LU5), and conglomerates and sandstones (Lithological Unit 6, LU6).

Detailed geomorphological mapping of the FanhõesTrancão test site allowed the identification and inventorying of 148 slope movements of rotational, translational and shallow translational types. In this study we only consider 
Table 1. Lithological units of the Fanhões-Trancão test site (north of Lisbon).

\begin{tabular}{lrr}
\hline Lithological unit & Area $\left(\mathrm{km}^{2}\right)$ & $(\%)$ \\
\hline LU1 & 0.62 & 3.1 \\
LU2 & 3.81 & 19.1 \\
LU3 & 1.42 & 7.1 \\
LU4 & 10.54 & 52.8 \\
LU5 & 0.38 & 1.9 \\
LU6 & 3.18 & 15.9 \\
Total & 19.95 & 100.0 \\
\hline
\end{tabular}

LU1: $\quad$ sandstones (upper Barremian - Aptian)

LU2: marls and marly limestones (Albian - middle Cenomanian)

LU3: limestones (upper Cenomanian)

LU4: Volcanic Complex of Lisbon (basalts and volcanic tuffs; upper Cretaceous)

LU5: lacustrine limestones (Paleogene)

LU6: conglomerates and sandtones (Paleogene)

the group of shallow translational slides (100 cases; Fig. 2) which represents $68 \%$ of the total number of landslide events in the test site.

Shallow translational slides in the study area are mostly single landslides moving along planar slip surfaces, and almost exclusively affect slope deposits lying upon an impermeable substratum, such as clays, marls, or volcanic tuffs. In most cases (ca 75\% of total events) the slip surface is located at the contact between the bedrock and the slope deposits. In the remaining cases the slip surface develops within the soil cover. Frequently the displaced material moves beyond the toe of the rupture zone. In such cases, the affected material generally breaks up and flows over the original topographic surface. Anyway the travel distance is always short, because of the dominant low relief energy of the area.

Landslides were not instrumentally monitored in the test site. Therefore, the kinematic behaviour of any particular slope movement was not studied in detail. Furthermore, there is no information about absolute velocity and acceleration for landslide displacements. Nevertheless, successive field observations have shown that landslide velocity should range from rapid $(1.8 \mathrm{~m} / \mathrm{h}$ to $3 \mathrm{~m} / \mathrm{min})$ to very rapid $(3 \mathrm{~m} / \mathrm{min}$ to $3 \mathrm{~m} / \mathrm{s}$ ), according to Cruden and Varnes (1996) classification.

Shallow translational slides in the study area have small dimensions (mean area, $1422 \mathrm{~m}^{2}$; total area, $142176 \mathrm{~m}^{2}$ ) and involve minor volumes of materials (mean volume, $364 \mathrm{~m}^{3}$; total volume, $35357 \mathrm{~m}^{3}$ ). Therefore, these landslides have a low "geometrical severity" and their consequences have only moderate economic significance, despite the high velocity generally involved. There is no information about people directly injured by this type of landslide, and the affected buildings are repaired with limited losses in the majority of cases. The most significant consequence of shallow translational slides is the widespread road disruption, responsible for relevant direct and particularly, indirect economic losses.

\section{Data collection and database construction}

The construction of a cartographic database, comprising the several maps used for landslide susceptibility assessment, was based on three different tasks: digitizing and editing of previous cartographic information, air-photo interpretation, and detailed field surveying (Fig. 3). Independent data layers, the variable cases considered, and the summarized data capture procedures are presented in Table 2.

The digital elevation model (DEM) was used to produce very significant derivative layers, including slope angle and slope aspect, which proved to be predisposing factors for the landslide activity. The DEM was created from contour lines ( $5 \mathrm{~m}$ equidistance) and elevation points that were initially in digital vector format (Microstation, dgn). These themes were imported to Ilwis 3.1 and rasterized. The union of the line and point data in a single file was done by overlaying the two themes. Finally, the DEM was generated by a linear interpolation based on the known pixel altitude values.

A pixel size of $5 \mathrm{~m}\left(25 \mathrm{~m}^{2}\right)$ was adopted to the DEM layer as well as the other themes presented in Table 2. Therefore, the test site is covered by digital images of $949 \times 841$ pixels (total area $=798109$ pixels).

The slope angle layer was directly derived from the DEM. For the landslide susceptibility assessment the slope angle was classified in 8 classes (Table 2), following an earlier proposal by Zêzere (1997) that showed good results for the study area.

The slope aspect layer was also based on the DEM. This variable represents the angle between the Geographic North and a horizontal plain for a certain point, classified in eight major orientations (N, NE, E, SE, S, SW, W, NW) with the addition of flat areas.

The transverse slope profile is an important variable that controls the superficial and subsurface hydrological regime of the slope. Concave, straight and convex slopes, as well flat areas were directly vectorized over a 1:2000 scale topographic map using Arcview 3.1. This layer includes also the motorway CREL (External Regional Circular of Lisbon) because of the huge impact of this infrastructure on the morphology of the study area. The motorway boundaries were extracted from the orthophoto map of the study area (1:10000 scale), and the resulting polygon was merged with the transverse slope profile information.

Lithology was obtained from the geological map of the region (1:50 000), taking in account the geotechnical properties of terrains. The geological boundaries of the 6 lithological units (Table 1) were verified and validated through aerial photo interpretation and fieldwork.

The superficial deposits layer was extracted from an analogical detailed geomorphological map supported by a field surveying at a 1:2000 scale. This map includes 6 main types of superficial deposits: alluvium, fine-grained terrace, recent flood terrace, valley fill deposit, old debris flow deposit, and colluvium. Special attention was given to the thickness of the colluvium, as this seems to be an important conditioning factor to shallow translational slides. An estimation of the 
Table 2. Thematic layers and favourability values of variables considering the total set of shallow translational slides. More significant results are highlighted in bold.

\begin{tabular}{|c|c|c|c|c|c|}
\hline $\begin{array}{l}\text { Thematic layer } \\
\text { Class }\end{array}$ & $\begin{array}{c}\text { Class } \\
\text { ID }\end{array}$ & $\begin{array}{l}\text { Number of pixels } \\
\text { of the class }\end{array}$ & $\begin{array}{l}\text { Number of landslide } \\
\text { pixels within the class }\end{array}$ & Favorability value & Data capture \\
\hline \multicolumn{6}{|l|}{ Slope angle } \\
\hline $0-5^{\circ}$ & 1 & 226885 & 180 & 0.0008 & Derived from DEM (pixel 5 m) \\
\hline $5-10^{\circ}$ & 2 & 265609 & 684 & 0.0026 & \\
\hline $10-15^{\circ}$ & 3 & 148501 & 1040 & 0.0070 & \\
\hline $15-20^{\circ}$ & 4 & 71497 & 1161 & 0.0161 & \\
\hline $20-25^{\circ}$ & 5 & 29093 & 650 & 0.0221 & \\
\hline $25-30^{\circ}$ & 6 & 27128 & 1004 & 0.0363 & \\
\hline $30-40^{\circ}$ & 7 & 23121 & 785 & 0.0334 & \\
\hline$>40^{\circ}$ & 8 & 6275 & 228 & 0.0357 & \\
\hline \multicolumn{6}{|l|}{ Slope Aspect } \\
\hline Flat & 1 & 1111 & 0 & 0.0000 & Derived from DEM (pixel $5 \mathrm{~m}$ ) \\
\hline $\mathrm{N}$ & 2 & 28818 & 162 & 0.0056 & \\
\hline NE & 3 & 61879 & 797 & 0.0128 & \\
\hline $\mathrm{E}$ & 4 & 111803 & 1386 & 0.0123 & \\
\hline SE & 5 & 151278 & 450 & 0.0030 & \\
\hline S & 6 & 206579 & 222 & 0.0011 & \\
\hline SW & 7 & 104967 & 491 & 0.0047 & \\
\hline $\mathrm{W}$ & 8 & 78902 & 1399 & 0.0176 & \\
\hline NW & 9 & 42732 & 825 & 0.0191 & \\
\hline \multicolumn{6}{|l|}{ Transversal profile of slope } \\
\hline Concave & 1 & 329984 & 3702 & 0.0112 & Directly drawn on a 1:2000 scale topographic \\
\hline Straight & 2 & 25121 & 289 & 0.0114 & map $(5 \mathrm{~m}$ contour $)$ \\
\hline Convex & 3 & 246793 & 1544 & 0.0062 & \\
\hline Flat & 4 & 187779 & 19 & 0.0001 & \\
\hline "CREL" & 5 & 8341 & 178 & 0.0211 & \\
\hline \multicolumn{6}{|l|}{ Lithology } \\
\hline LU1 & 1 & 24976 & 435 & 0.0173 & Geological map (1:50 000 scale); validation \\
\hline LU2 & 2 & 152553 & 2602 & 0.0169 & with aerial photo interpretation and field work \\
\hline LU3 & 3 & 56710 & 570 & 0.0100 & \\
\hline LU4 & 4 & 421708 & 2035 & 0.0048 & \\
\hline LU5 & 5 & 15097 & 0 & 0.0000 & \\
\hline LU6 & 6 & 127065 & 90 & 0.0007 & \\
\hline \multicolumn{6}{|l|}{ Superficial deposits } \\
\hline Alluvium & 1 & 48835 & 0 & 0.0000 & Field work; detailed geomorphological \\
\hline Colluvium thickness $<0.5 \mathrm{~m}$ & 2 & 386004 & 929 & 0.0024 & mapping (scale 1:2000) \\
\hline Colluvium thickness $\geq 0.5 \mathrm{~m}$ & 3 & 313006 & 4797 & 0.0152 & \\
\hline Old debris flow deposit & 4 & 12238 & 0 & 0.0000 & \\
\hline Fine-grained terrace & 5 & 31511 & 0 & 0.0000 & \\
\hline Recent flood terrace & 6 & 1896 & 6 & 0.0032 & \\
\hline Valley fill deposit & 7 & 4619 & 0 & 0.0000 & \\
\hline \multicolumn{6}{|l|}{ Geomorphological units } \\
\hline Active erosion channel & 1 & 8832 & 100 & 0.0113 & Field work; detailed geomorphological \\
\hline Alluvial plain & 2 & 49218 & 0 & 0.0000 & mapping (scale 1:2000) \\
\hline Front of cuesta & 3 & 37250 & 696 & 0.0185 & \\
\hline Other anaclinal slope & 4 & 12893 & 36 & 0.0028 & \\
\hline Cataclinal slope & 5 & 274017 & 513 & 0.0019 & \\
\hline Valley slope & 6 & 227207 & 4268 & 0.0186 & \\
\hline U-shaped valley & 7 & 48364 & 100 & 0.0021 & \\
\hline Fluvial terrace & 8 & 43762 & 0 & 0.0000 & \\
\hline Flat surface & 9 & 84471 & 19 & 0.0002 & \\
\hline Quarry & 10 & 12893 & 36 & 0.0028 & \\
\hline Other anthropogenic surface & 11 & 7565 & 0 & 0.0000 & \\
\hline \multicolumn{6}{|l|}{ Land use } \\
\hline Trees & 1 & 57173 & 205 & 0.0036 & Interpretation of a digital orthophoto map at \\
\hline Dense shrubs & 2 & 152364 & 1966 & 0.0128 & a scale 1:10000; field work verification \\
\hline Herbaceous vegetation & 3 & 399689 & 3079 & 0.0077 & \\
\hline Cultivated & 4 & 82039 & 103 & 0.0013 & \\
\hline Urban green space & 5 & 8289 & 7 & 0.0008 & \\
\hline Urban area & 6 & 98555 & 372 & 0.0038 & \\
\hline
\end{tabular}




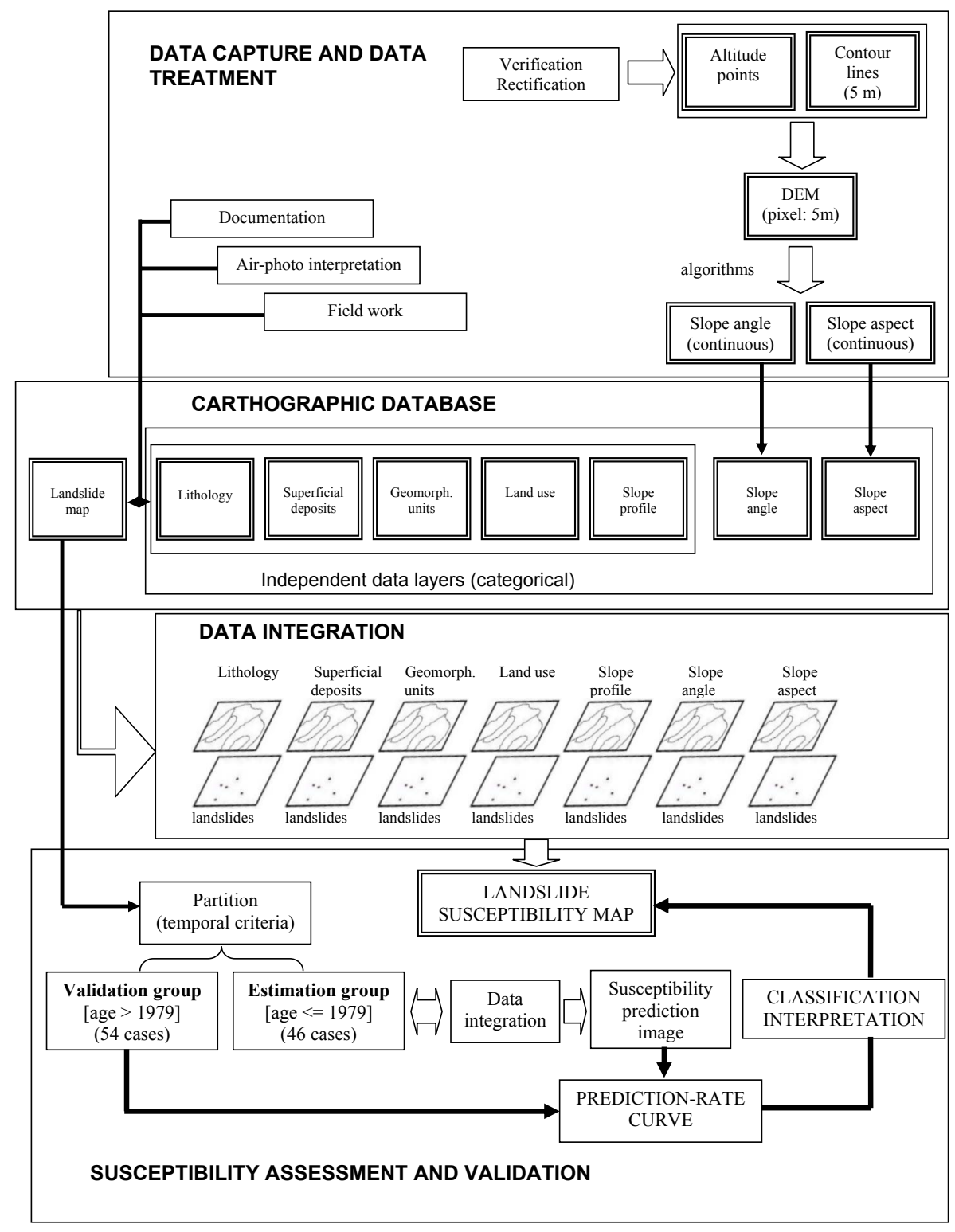

Fig. 3. General methodology from data capture and treatment to landslide susceptibility assessment and validation. deposit depth was made in the field and two different subclasses were considered: colluvium thickness $<0.5 \mathrm{~m}$ and colluvium thickness $\geq 0.5 \mathrm{~m}$. The vectoring of the different superficial deposits classes was made over field maps using Arcview 3.1.

The geomorphological units layer includes 11 classes (active erosion channel, alluvial plain, front of cuesta, other anaclinal slope, cataclinal slope, valley slope, U-shaped valley, fluvial terrace, flat surface, quarry, and other anthropogenic surface). This layer was drawn over the topographic map (1:2000 scale) in the Arcview 3.1 environment, taking in account information from the detailed geomorphological map.

The land use layer classifies the land use and vegetation type in a stratified general type mode. The classification takes in account the characteristics that were believed to be controlling factors for landslide activity in the study area (Zêzere, 1997; Zêzere et al., 1999). The main factors were the density and size of the vegetation cover (mainly considering root stabilization effects) and the urban and human intervention areas, usually densely constructed and generally more stable with respect to landslide activity in the test site. Land use was classified into urban areas, urban green spaces, cultivated areas (small size vegetables, vineyards, etc.), dense shrubs (generally very dense small to medium size shrubs), herbaceous vegetation (corresponding usually to abandoned areas which were earlier cultivated), and trees (tree cover not necessarily dense and not attaining a forest status). The obtained data are the result of an orthophoto map interpretation $(1: 10000$ scale) in a polygon coverage shape file, including field validation.

Landslides were recognized and mapped in the field at the 1:2000 scale. A standard form was completed for each landslide including landslide typology, absolute age, state of activity, morphometric parameters and slope properties. The 

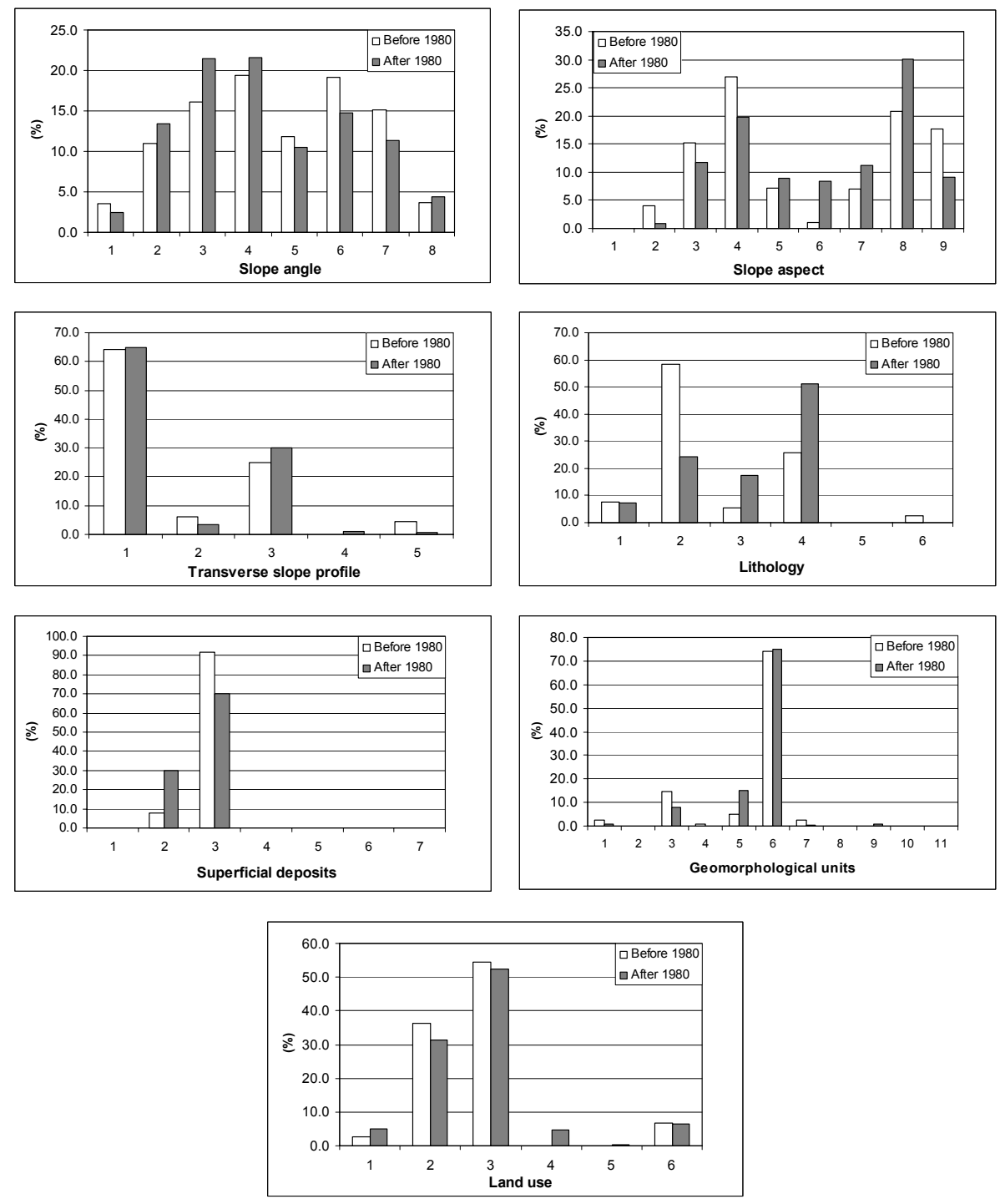

Fig. 4. Landslide frequency within classes of landslide predisposing factors. For thematic classes description see Class ID in Table 2. vectoring of slope movements was done over field maps in the Arcview 3.1. environment. Each landslide was attributed with a unique ID and a link to the landslide database was established allowing the direct production of layers reflecting any variable from the database (e.g. absolute age of landslide; state of activity).

The quality and reliability of the landslide distribution map should be considered high (Soeters and Van Westen, 1996), as the entire slope movements were directly identified and mapped in the field. Nevertheless, landslides of older age are certainly under-represented in the database, because of the rapid disappearance of landslide morphology in the landscape by erosion processes and anthropogenic actions (e.g. farming activity and road construction).

After being completed, all the thematic layers were imported to Ilwis 3.1. and rasterized for analytical purposes. Figure 4 shows the frequency distribution of landslides within different classes of the considered predisposing factors.

\section{Landslide susceptibility assessment and validation}

The method for landslide susceptibility assessment used in this study, is based on the concept of the favourability function (Chung and Fabbri, 1993; Fabbri et al., 2002). It assumes that the likelihood of landslide occurrence can be measured by statistical relationships between past landslides of a given type and specified spatial data sets. It is assumed that any landslide occurs under particular conditions that can be characterized by these spatial data sets, which are considered as independent conditioning factors. Thus, the prediction of landslide susceptibility is considered as the joint conditional probability that a given small area will be affected by a future landslide conditioned by the physical characteristics of the area.

The calculation of prior and conditional probabilities is a compulsive condition for the development of the remaining procedures, and represents the first step of the cartographic data integration. The calculated probabilities, based on the 


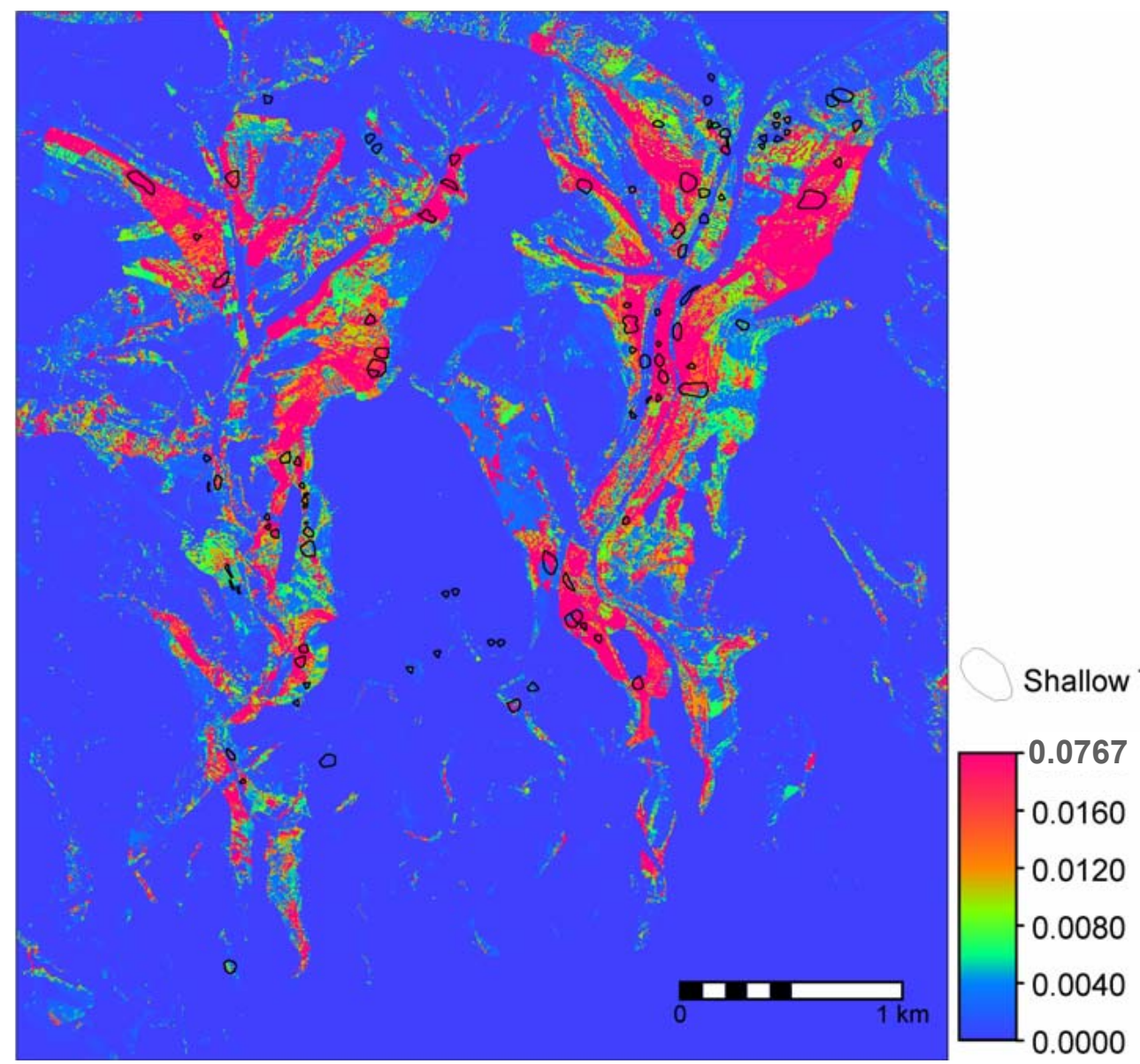

Fig. 5. Non-classified shallow translational slide susceptibility map of the Fanhões-Trancão test site, based on the complete landslide data set (100 cases).

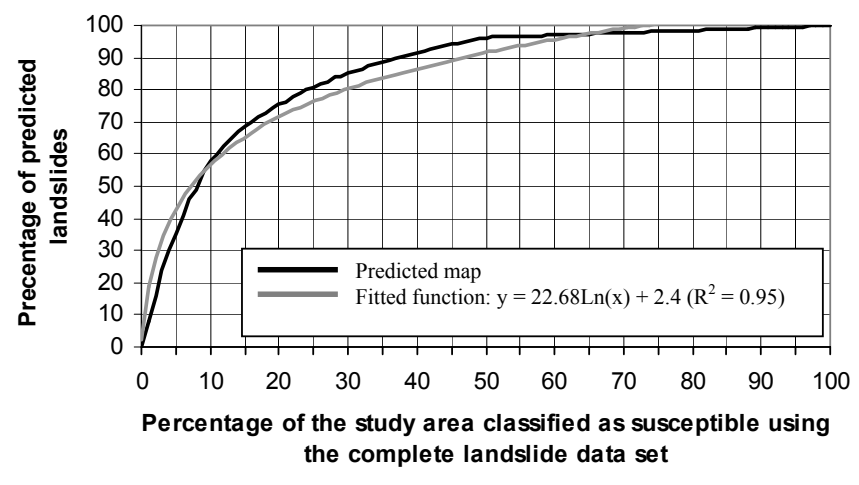

Fig. 6. Success-rate curve of the susceptibility assessment based on the complete landslide data set.

correlation between the landslide map and several independent data layers (Fig. 3), and on the relationship between affected areas and total areas, are the following:

i) Prior probability of finding a landslide

affected area/total area ii) Prior probability of finding a class of a layer

$$
\text { class area/total area }
$$

iii) Conditional probability of finding a landslide in each class, for each layer

$$
1-\left(1-\frac{1}{\text { class area }}\right)^{\text {affected area in the class }}
$$

Results obtained from Eq. (3) are presented in Table 2, and can be considered as Favourability values (or susceptibility indicators) of the different spatial units within a given layer, if this layer is independent from the other factors (Chung and Fabbri, 1993; Remondo et al., 2003).

Data integration of all variables was made using the Joint Conditional Probability Function, resulting in over 15636 unique condition sub-areas obtained by the overlay of all the thematic layers (Chung et al., 1995).

The probability of finding a landslide given $\mathrm{n}$ data layers, using the conditional probability integration rule, can be obtained with the following expression (Chung and Fabbri, 


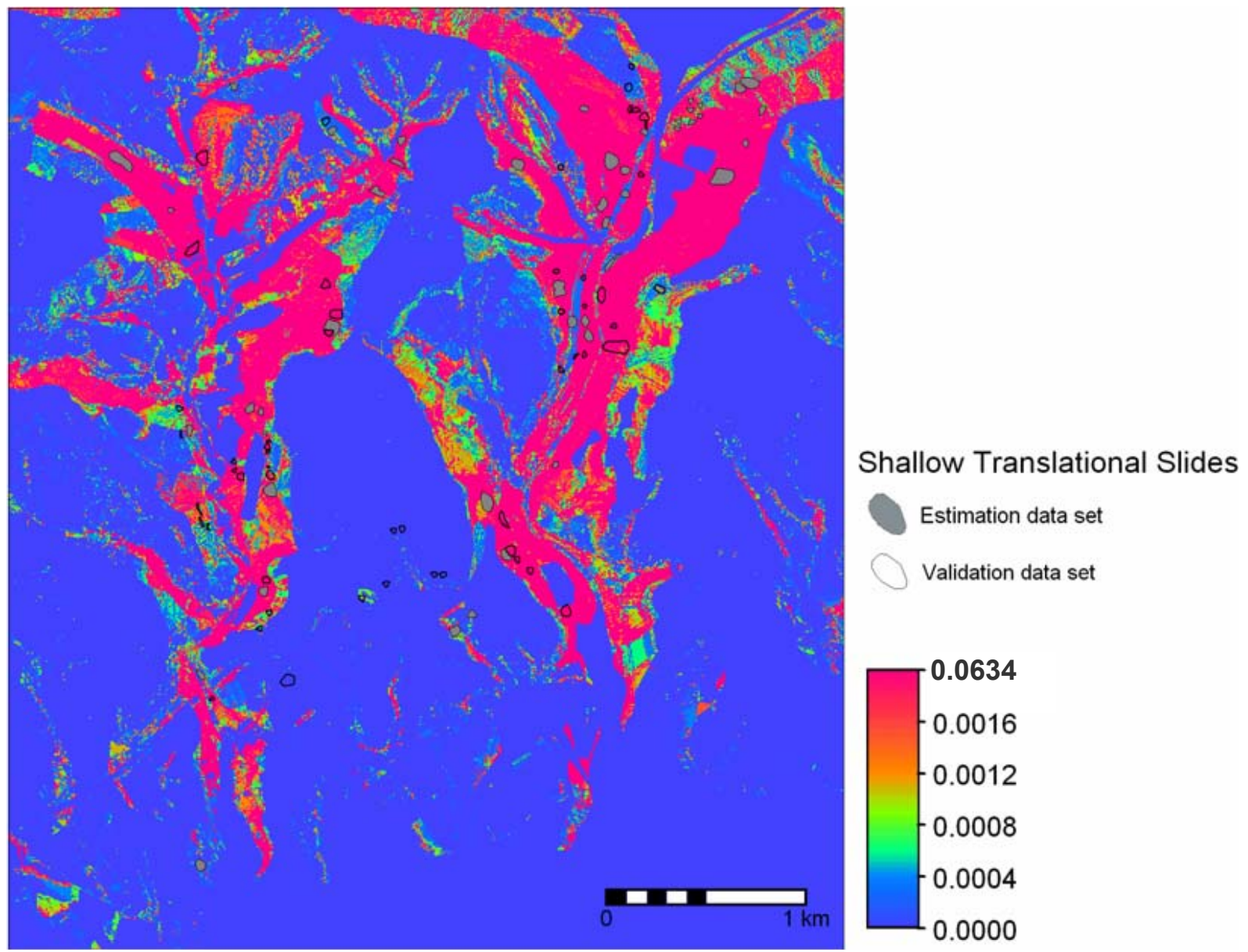

Fig. 7. Non-classified shallow translational slide susceptibility map of the Fanhões-Trancão test site, based on Estimation Group landslides (age $\leq 1979,46$ cases).

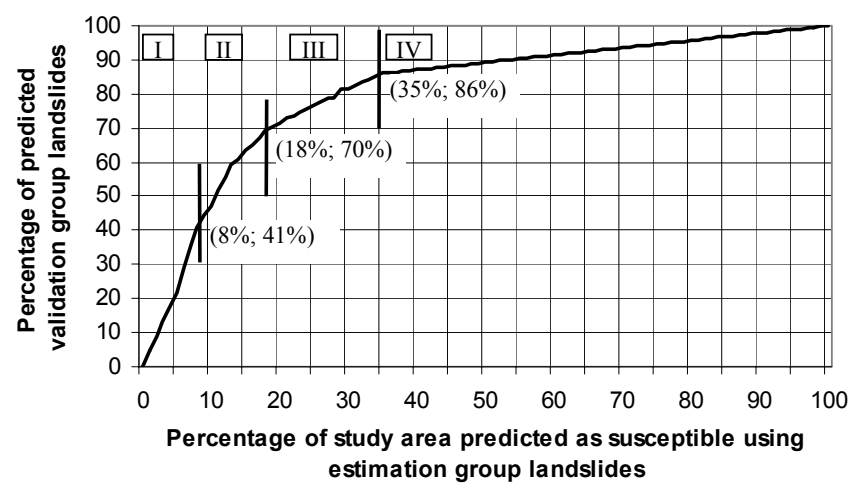

Fig. 8. Prediction-rate curve of the susceptibility assessment based on Estimation Group landslides (age $\leq 1979,46$ cases) and compared with Validation Group landslides (age > 1979, 54 cases).

1999):

$$
\begin{aligned}
& \frac{\left(P_{p_{L 1}} \times P_{p_{L 2}} \times \ldots \times P_{p_{L n}}\right)}{P_{\text {pslide }}^{L_{n-1}} \times\left(L_{1} \times L_{2} \times \ldots \times L_{n}\right)} \\
& \quad \cdot\left(C_{p_{L 1}} \times C_{p_{L 2}} \times \ldots \times C_{p_{L n}}\right)
\end{aligned}
$$

where $L_{1}, L_{2}, \ldots, L_{n}$ are the several data layers used as independent variables, $\left(L_{1} \times L_{2} \times \ldots \times L_{n}\right)$ represents the prior probability of finding the $n$ data layers in the test site, $C_{p}$ is the conditional probability of finding a landslide in a class of each layer, and $P_{p}$ and $P_{\text {pslide }}$ are the prior probabilities of finding, respectively, a class and a landslide in the study area.

Results from Eq. (4) range from 0 to 1 and can be interpreted as estimators of the relative spatial probability (or susceptibility) of landslide occurrence in the future.

The methodological approach was first applied using the total set of shallow translational slides (100 cases). The computed favourability (susceptibility) values for each pixel are presented in a pseudo-colour continuous scale from 0 (lower susceptibility) to 0.0767 (higher susceptibility), in a non-classified susceptibility map of the study area (Fig. 5). Figure 6 shows the success-rate curve of the susceptibility assessment, computed after sorting into descending order the 798109 susceptibility values (one for each pixel). The results are very satisfactory: the $10 \%$ high susceptible area includes $58 \%$ of the total landslide area, while the $20 \%$ high susceptible area covers more than $75 \%$ of the total unstable area. The success-rate curve adjust quite well to a linear logarithmic function $(\mathrm{y}=22.68 \operatorname{Ln}(\mathrm{x})+2.4)$, being $\mathrm{R}^{2}=0.95$. 


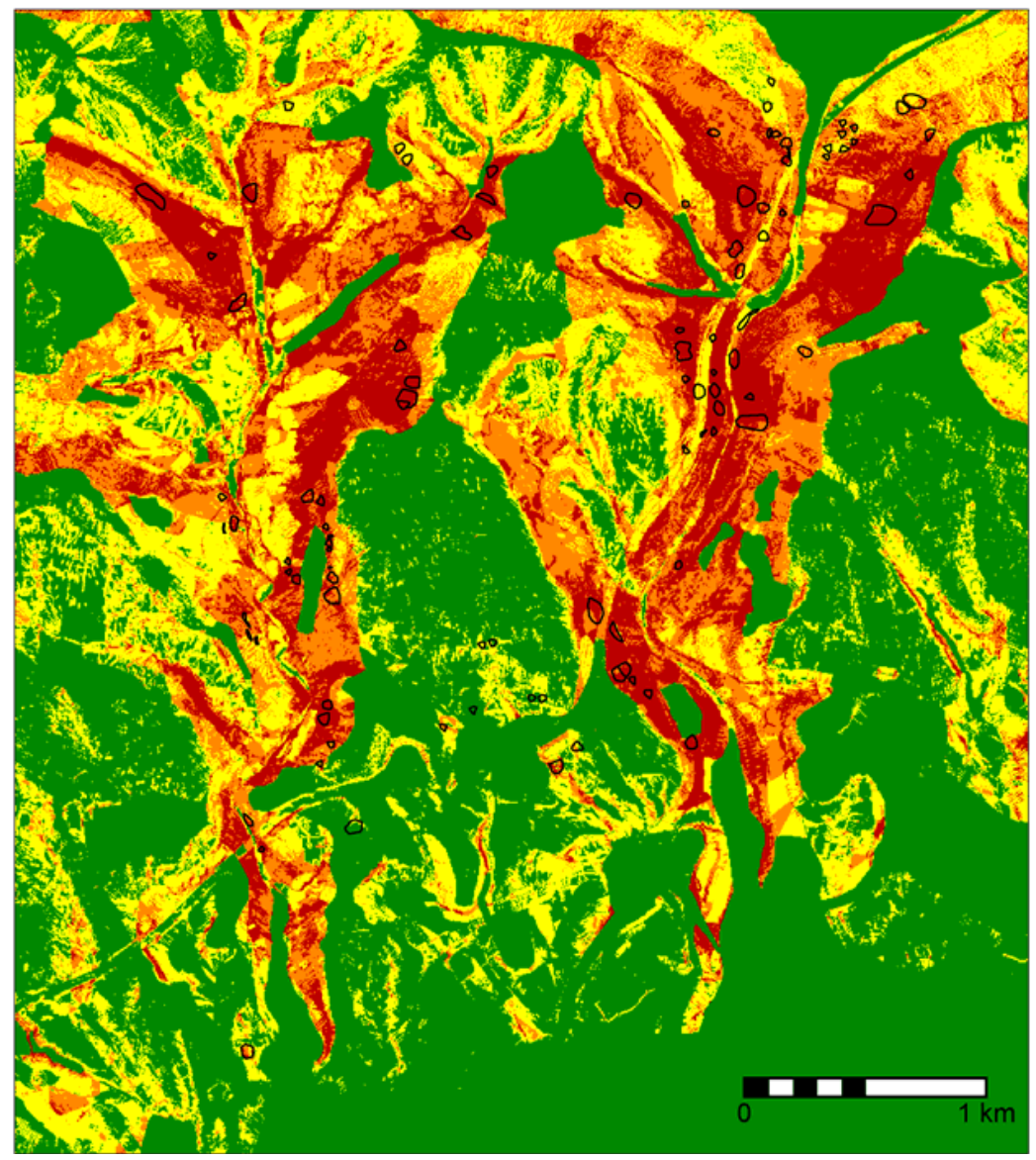

\section{Shallow Translational Slides}

I - Top $8 \%$

II $-8-18 \%$

III $-18-35 \%$

IV $-35-100 \%$

Fig. 9. Shallow translational slide susceptibility map of the Fanhões - Trancão test site, classified according to the prediction-rate curve.

Although these results are good, the success-rate curve is not able to validate the susceptibility assessment. The curve measures the "goodness of fit" assuming that the model is correct, as it is based on the comparison between a prediction image (Fig. 5) and the landslide data set used in the modelling procedure (Chung and Fabbri, in press).

In order to validate the results of the susceptibility assessment, the landslide data set was divided in two parts using a temporal criterion (Fig. 3): Estimation Group (age $\leq 1979$, 46 cases) and Validation Group (age > 1979, 54 cases). The first sub-set was used to obtain a new prediction image (Fig. 7), using the same data integration and representation procedures as described for the susceptibility assessment based on the total landslide data set. The second sub-set was compared with the prediction results for validation (Fabbri et al., 2002).

The computed prediction-rate curve (Fig. 8) is obtained by comparing the second susceptibility map with the distribution of the validation group landslides, which is then used to interpret and classify the original predicted susceptibility map using all the slope movements (Fig. 5), as proposed by Chung and Fabbri (in press).

Interpretation of Fig. 8 allows the identification of the following susceptibility classes:
(I) The most susceptible 63849 pixels (the largest susceptibility values that cover $8 \%$ of the study area) include $41 \%$ of the area of validation group landslides;

(II) The 2nd susceptibility class includes the 79810 pixels (10\% of the study area) with susceptibility values immediately lower than class (I). This class justifies $29 \%$ of the validation group landslides;

(III) The 3rd susceptibility class corresponds to the next 135679 pixel susceptible values (17\% of the total area), and includes $16 \%$ of the validation group landslides;

(IV) The least susceptible class includes the $65 \%$ of the study area (518771 pixels) with the lower susceptibility values. Although this is the largest area, this class includes only $14 \%$ of the validation group landslides.

The critical limits of $8 \%, 18 \%$ and $35 \%$ of the study area, defined according to different gradients of the prediction curve, were take in account to classify the susceptibility map produced with the complete landslide data set (Fig. 5) and the result is presented in Fig. 9. Assuming that the behaviour of future slope instability will be similar to that measured in the past, we can predict that future shallow translational slides in the test site will occur on the susceptibility classes, 


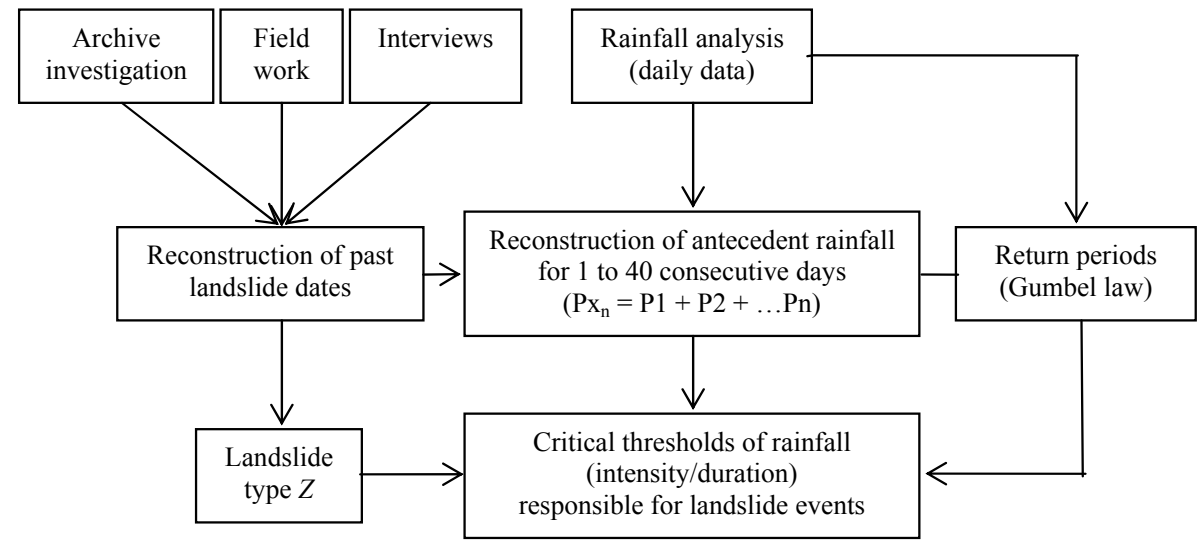

Fig. 10. Methodology for rainfall triggering of landslides analysis. in a non-specified period of time, according to the values obtained from the prediction-rate curve (Fig. 8); i.e. $41 \%, 29 \%$, $16 \%$ and $14 \%$ of future landslides will be located in the 1 st, 2nd, 3rd and 4th susceptibility classes, respectively.

\section{Definition of probabilistic hazard scenarios through landslide frequency analysis}

As Chung and Fabbri (in press) point out, the validation process allows an empirical measure of the spatial support so that the relationships between the prediction-rate curve and the susceptibility map can be transformed into probabilities of occurrence. Nevertheless, some more assumptions on future landslides are needed to estimate the probability. Information about expected number and expected size of future landslides that are to occur within a specified time interval are crucial to achieve probabilities, thus transforming susceptibility in hazard. Such information can be obtained, for the study area, through frequency analysis of the landslides.

Previous works have shown that most slope movements have a clear climatic signal in the Lisbon area. In the particular case of shallow translational slides a strong relationship exists between landslide occurrence and very intense and exceptional rainfall episodes (Zêzere et al., 1999; Zêzere, 2000; Zêzere and Rodrigues, 2002).

The adopted method to relate the historic occurrence of landsliding to rainfall (Fig. 10) includes the reconstruction of cumulative rains from 1 to 40 days for the periods of major slope instability observed during the last four decades in the study area. Longer durations (above 40 days) were not considered because it is assumed that shallow failures are not usually triggered by long lasting rainfall periods. A Gumbel law was applied to compute the return period of the obtained rainfall intensity-duration combinations. Critical pairs of rainfall amount-duration were defined as proposed by D'Ecclesiis et al. (1991), assuming as critical values the extreme combinations from the statistical point of view. Obtained results are presented in Table 3 and critical amountdurations are highlighted in bold.
Table 4 summarized the recognized dates of past shallow translational activity within the Fanhões-Trancão test site, as well as the total affected area in each of the rainfall triggered landslide events.

Let us assume now that the rainfall combination (amountduration) that produced slope instability in the past will produce the same effects each time they occur in the future (i.e. same type of landslides and similar total affected area). As the return periods of triggering events are known, different scenarios can be modelled, each one corresponding to a specific return period.

Taking in account both the information from the prediction-rate curve (Fig. 8) and the classes of susceptibility map (Fig. 9), the conditional probability that a pixel will be affected by a shallow translational side in the future can be estimated for each particular scenario by:

$P=1-\left(1-\frac{T_{\text {affected }}}{T_{y}} \cdot p\right.$ red $)$,

where:

$T_{\text {affected }}=$ total area to be affected by landslides in a scenario $(x)$;

$T_{y}=$ total area of susceptibility class $y$

$p$ red $=$ prediction value of susceptibility class $y$.

Table 5 summarizes the results obtained for three particular rainfall triggering scenarios: (1) $128 \mathrm{~mm}$ in 3 days; 8.5 years return period; (February 1979); (2) $164 \mathrm{~mm}$ in one day; 200 years return period (November 1983); and (3) $217 \mathrm{~mm}$ in 15 days; 4.5 years return period (November 1989).

The cartographic expression of probabilities presented in Table 5 allows the modelling of three different landslide hazard scenarios, each one corresponding to a specific rainfall combination with a specific return period. The spatial distribution of susceptibility classes remains unchanged in all hazard scenarios; differences are to be found on the probability for each pixel to be affected by a shallow translational slide, as well as on the corresponding return period.

Consider now that a small factory of size $20 \mathrm{~m} \times 25 \mathrm{~m}$ $\left(500 \mathrm{~m}^{2}\right.$, or 20 pixels) is build up within the most hazardous 
Table 3. Cumulative rainfall from 1 to 40 days and corresponding return periods for the shallow translational slide events recognized in the Fanhões-Trancão test site (rainfall data from S. Julião do Tojal, period: 1956-2001; R - rainfall (mm); R.P. - return period (years).

\begin{tabular}{|c|c|c|c|c|c|c|c|c|c|}
\hline & & 1 day & 2 days & 3 days & 5 days & 10 days & 15 days & 30 days & 40 days \\
\hline \multirow[t]{2}{*}{25 November 1967} & $\mathrm{R}(\mathrm{mm})$ & 137.0 & 141.5 & 141.5 & 141.5 & 155.7 & 176.9 & 248.5 & 307.4 \\
\hline & R.P. (y) & 60 & 28 & 14 & 5.5 & 3 & 2.5 & 2.5 & 3 \\
\hline \multirow[t]{2}{*}{10 February 1979} & $\mathrm{R}(\mathrm{mm})$ & 26.0 & 66.0 & 128.2 & 137.9 & 160.5 & 203.5 & 335.2 & 351.1 \\
\hline & R.P. (y) & 1.1 & 2 & 8.5 & 4.5 & 3 & 3.5 & 5.5 & 4 \\
\hline \multirow[t]{2}{*}{18 November 1983} & $\mathrm{R}(\mathrm{mm})$ & 163.7 & 167.4 & 205.4 & 230.3 & 265.2 & 349.9 & 403.7 & 407.3 \\
\hline & R.P. (y) & 200 & 80 & 130 & 65 & 25 & 38 & 13 & 7 \\
\hline \multirow{2}{*}{25 February 1987} & $\mathrm{R}(\mathrm{mm})$ & 51.8 & 60.3 & 78.3 & 98.3 & 99.8 & 141.5 & 217.9 & 232.6 \\
\hline & R.P. (y) & 2 & 1.7 & 2 & 1.8 & 1.3 & 1.8 & 1.8 & 1.6 \\
\hline \multirow[t]{2}{*}{25 November 1989} & $\mathrm{R}(\mathrm{mm})$ & 38.0 & 43.0 & 52.8 & 91.3 & 164.7 & 216.5 & 217.6 & 277.7 \\
\hline & R.P. (y) & 1.4 & 1.2 & 1.2 & 1.7 & 3.5 & 4.5 & 1.8 & 2.2 \\
\hline \multirow[t]{2}{*}{5 December 1989} & $\mathrm{R}(\mathrm{mm})$ & 30.1 & 60.3 & 98.5 & 98.5 & 115.8 & 207.1 & 333.4 & 333.4 \\
\hline & R.P. (y) & 1.2 & 1.3 & 3.5 & 1.8 & 1.6 & 4.0 & 5.5 & 3.5 \\
\hline \multirow[t]{2}{*}{9 January 1996} & $\mathrm{R}(\mathrm{mm})$ & 66.5 & 69.0 & 77.0 & 95.2 & 149.1 & 259.9 & 341.5 & 372.3 \\
\hline & R.P. (y) & 3.5 & 2.2 & 1.9 & 1.7 & 2.5 & 8 & 6 & 5 \\
\hline
\end{tabular}

Table 4. Age and total affected areas by shallow translational slides within the Fanhões-Trancão test site.

\begin{tabular}{lrrrr}
\hline Age & $\mathrm{N}$ & $(\%)$ & $\begin{array}{c}\text { Total affected } \\
\text { area }\left(\mathrm{m}^{2}\right)\end{array}$ & $(\%)$ \\
& & \multicolumn{3}{c}{ (\% } \\
\hline 1967 or prior & 22 & 22.0 & 44017 & 31.0 \\
February 1979 & 24 & 24.0 & 44440 & 31.3 \\
November 1983 & 40 & 40.0 & 47125 & 33.1 \\
February 1987 & 4 & 4.0 & 3283 & 2.3 \\
November 1989 & 3 & 3.0 & 1315 & 0.9 \\
December 1989 & 3 & 3.0 & 996 & 0.7 \\
January 1996 & 4 & 4.0 & 1000 & 0.7 \\
Total & 100 & 100.0 & 142176 & 100.0 \\
\hline
\end{tabular}

class in the test site. An estimation of the conditional probability that a future shallow translational slide will affect the factory can be obtained for each of the considered scenarios by:

$P^{\prime}=-\left(1-\frac{T_{\text {affected }}}{63859(=T I)} \cdot 0.4(=p \operatorname{red} \mathrm{I})\right)^{20(=\text { size of factory })}$

where:

$T_{\text {affected }}=$ total area to be affected by landslides in a scenario $(x)$;

$T I=$ total area of susceptibility class $I$;

predI $=$ prediction value of susceptibility class $I$.

Thus, the probability that a part of the factory will be involved in landslide activity obtained with Eq. (6) is $20.5 \%$ for scenario (1), $21.6 \%$ for scenario (2), and $0.7 \%$ for scenario (3).

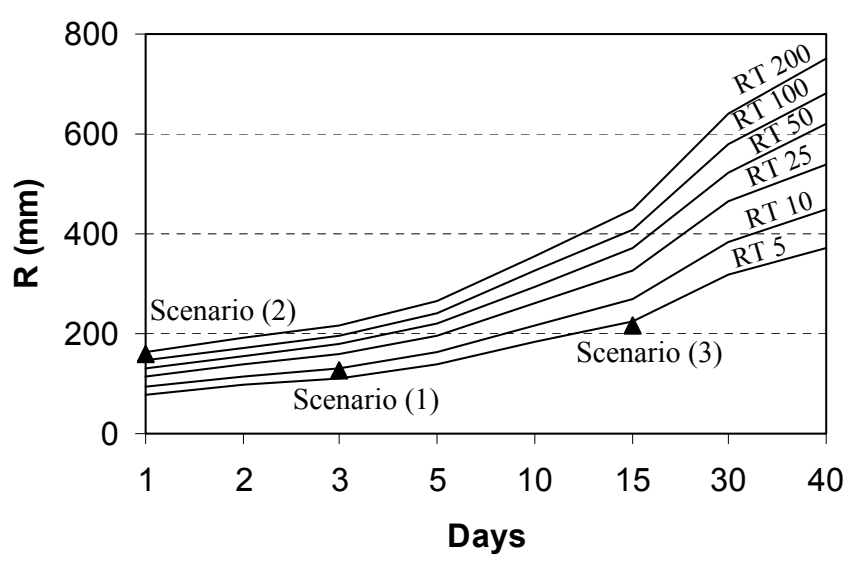

Fig. 11. Return periods for rainfall amount-duration combinations in the Fanhões-Trancão test site (rainfall data from S. Julião do Tojal, period: 1956-2001). $R T=$ return time in years.

\section{Summary and conclusions}

Following Varnes et al. (1984) definition of landslide hazard as the probability of occurrence of a potential damaging phenomenon within a given area and in a given period of time, a general methodology for landslide hazard assessment was applied in a test site in the area north of Lisbon, taking in account both the landslide susceptibility and the instability triggering factors.

Landslide susceptibility was evaluated assuming that future landslides can be predicted by statistical relationships between past landslides and the spatial data set of the landslide predisposing factors. Thus, landslide susceptibility was assessed using the Joint Conditional Probability Function, over 15636 unique-condition terrain units obtained in a raster basis by the overlay of seven thematic layers. The methodological approach was first applied to the total set of 
Table 5. Calculation of probabilities for landslide hazard assessment working on a scenario basis.

\begin{tabular}{|c|c|c|c|c|c|c|}
\hline \multirow{3}{*}{\multicolumn{2}{|c|}{$\begin{array}{l}\text { Landslide susceptibility } \\
\text { class }\end{array}$}} & \multirow[b]{3}{*}{$\begin{array}{c}\text { Area } \\
\text { (number of pixels) } \\
\text { (pixel }=5 \mathrm{~m})\end{array}$} & \multirow[b]{3}{*}{$\begin{array}{l}\text { Predictive value of } \\
\text { susceptibility class }\end{array}$} & \multicolumn{3}{|c|}{$\begin{array}{l}\text { Probability to each pixel to be } \\
\text { affected by a landslide }\end{array}$} \\
\hline & & & & \multicolumn{3}{|c|}{ Scenarios } \\
\hline & & & & $\begin{array}{c}\text { (1) } \\
\text { February } 1979\end{array}$ & $\begin{array}{c}(2) \\
\text { November } 1983\end{array}$ & $\begin{array}{c}(3) \\
\text { November } 1989\end{array}$ \\
\hline I & Top 8\% & 63849 & 0.41 & 0.0114 & 0.0121 & 0.00034 \\
\hline II & $8-18 \%$ & 79810 & 0.29 & 0.0065 & 0.0068 & 0.00019 \\
\hline III & $18-35 \%$ & 135679 & 0.16 & 0.0021 & 0.0022 & 0.00006 \\
\hline IV & $35-100 \%$ & 518771 & 0.14 & 0.0005 & 0.0005 & 0.00001 \\
\hline
\end{tabular}

100 shallow translational slides. The computed favourability values of considered variables pointed out the importance of slope angle higher than $20^{\circ}$, valley slopes, lithological units 1 (sandstones) and 2 (marls, with marly limestone and limestone intercalations), colluvium thicker than $0.5 \mathrm{~m}$, and dense shrubs, as main landslide conditioning factors.

Validation of the susceptibility assessment was made partitioning the total landslide data set in two parts adopting a temporal criterion. A new prediction image was constructed using the older slope movements, and a prediction-rate curve was computed comparing the recent landslide group with the predicted results. The computation of the prediction-rate curve is the key strategic element to interpret the landslide prediction and to go further on landslide hazard. In fact, following the proposal of Chung and Fabbri (in press), this curve was used not only to interpret but to classify in a consistent way the original susceptibility map obtained with the total landslide data set.

Transformation of landslide susceptibility into landslide hazard implies available information about the expected number and size of future landslides that are to occur within a defined time span. As landslides in the study area are mostly triggered by rainfall, such information was obtained studying the historic record of regional slope instability, and the relationships with the intensity, duration and frequency of the rainfall triggering events. The definition of amount-duration combinations of rainfall responsible for past landslide events was followed by the calculation of the relevant return periods. Assuming that the same rainfall situations that produced shallow translational slides in the past will produce the same effects in the future (i.e. similar total affected area), different landslide hazard scenarios can be computed, each one corresponding to a specific return period (Fig. 11). Nevertheless it is necessary to stress that different rainfall amount-duration combinations with the same return period can produce different landslide hazard scenarios. Furthermore, the same landslide hazard scenario can be related to different rainfall combinations with different return periods.
The coupling between the susceptibility map, predictionrate curve and return periods of critical rainfall triggering events enable the presentation of landslide hazard as the probability of each pixel to be affected by a shallow translational slides, on a scenario basis. The computation of landslide hazard at a probabilistic basis is of critical importance to decision-makers responsible for civil protection and urban planning because the obtained results can be easily integrated with information about vulnerability in the decision process, through a cost-benefit analysis.

Acknowledgements. This paper is part of the European Commission project "Assessment of Landslide Risk and Mitigation in Mountain Areas, ALARM" (contract EVG1-CT-2001-00038), Fifth Framework Programme.

The authors are grateful to A. Hansen and P. Aleotti whose pertinent comments and suggestions improved the quality of this paper.

Edited by: P. Reichenbach

Reviewed by: P. Aleotti and another referee

\section{References}

Aleotti, P. and Chowdhury, R.: Landslide hazard assessment: summary review and new perspectives, Bull. Eng. Geol. Env., 58, 21-44, 1999.

Carrara, A., Cardinali, M., Guzzetti, F., and Reichenbach, P.: GIS technology in mapping landslide hazard, edited by Carrara, A and Guzzetti, F., Geograph. Inf. Syst. in Assess. Nat. Hazards, Kluwer Academic Publishers, 135-175, 1995.

Carrara, A., Guzzetti, F., Cardinali, M., and Reichenbach, P.: Current limitations in modeling landslide hazard, edited by Buccianti, A., Nardi, G., and Potenza, R., Proceedings of IAMG'98, 195-203, 1998.

Cruden, D. M. and Varnes, D. J.: Landslide Types and Processes, edited by Turner, A. K. and Schuster, R. L., Landslides. Investigation and Mitigation. Transportation Research Board, Special Report 247, National Academy Press, Washington D.C., 36-75, 1996.

Chung, C. F. and Fabbri, A.: The representation of geoscience information for data integration, Nonrenewable Resources, 2 (2), 122-138, 1993. 
Chung, C. F. and Fabbri, A.: Probabilistic prediction models for landslide hazard mapping, Photogrammetric Engineering and Remote Sensing, 65 (12), 1389-1399, 1999.

Chung, C. F. and Fabbri, A.: Systematic procedures of landslidehazard mapping for risk assessment using spatial prediction models, edited by Glade, T., Anderson, M. G., and Crozier, M. J., Landslide Hazard and Risk, John Wiley \& Sons Ltd., London (in press)

Chung, C. F., Fabbri, A., and Van Westen, C. J.: Multivariate regression analysis for landslide hazard zonation, edited by Carrara, A. and Guzzetti, F., Geograph. Inf. Syst. in Assessing Nat. Hazards, Kluwer Academic Publishers, Dordrecht, 107-133, 1995.

D'Ecclesiis, G., Grassi, D., Merenda, L., Polemio, M., and Sdao, F.: Evoluzione geomorfologica di un' area suburbana di Castronuovo S. Andrea (PZ) ed incidenza delle piogge su alcuni movimenti di massa, Geologia Applicata e Idrogeologia, XXVI, Bari, 141163, 1991.

Fabbri, A., Chung, C. F., Napolitano, P., Remondo, J., and Zêzere, J. L.: Prediction rate functions of landslide susceptibility applied in the Iberian Peninsula, edited by Brebbia, C. A., Risk Analysis III, Series: Management Information Systems, WIT Press, Southampton, Boston, vol. 5, 703-718, 2002.

Guzzetti, F., Carrara, A., Cardinali, M., and Reichenbach, P.: Landslide hazard evaluation: a review of current techniques and their application in a multi-scale study, Central Italy, Geomorphology, Elsevier, 31, 181-216, 1999.

Hansen, A.: Landslide hazard analysis, edited by Brunsden, D. and Prior, D. B., Slope Instability, John Wiley and Sons, Chichester, 523-602, 1984.

Hutchinson, J. N.: Landslide hazard assessment, keynote paper, in: Landslides, Proceedings of the 6th International Symposium on Landslides, edited by Bell, D., Balkema, Rotterdam, 1805-1841, 1995.

Irigaray, C., Chacón, J., and Fernández, T.: Methodology for the analysis of landslide determinant factors by means of a GIS: Application to the Colmenar area (Malaga, Spain), edited by
Chacón, J., Irigaray, C., and Fernández, T., Landslides, Balkema, Rotterdam, 163-172, 1996.

Remondo, J., González, A., Díaz de Terán, J. R., Fabbri, A., and Chung, C. F.: Validation of Landslide Susceptibility Maps, Examples and Applications from a Case Study in Northern Spain, Natural Hazards, Kluwer Academic Publishers, 2003 (in press).

Soeters, R. and Van Westen, C. J.: Slope Instability Recognition, Analysis and Zonation,in: Landslides. Investigation and Mitigation. Transportation Research Board, Special Report, edited by Turner, A. K. and Schuster, R. L., National Academy Press, Washington D.C., 129-177, 1996.

Varnes, D. J. and Intern. Association of Engineering Geology Commission on Landslides and Other Mass Movements on Slopes: Landslide hazard zonation: a review of principles and practice, UNESCO, Paris, 1984.

Yin, K. L. and Yan, T. Z.: Statistical prediction models for slope instability of metamorphosed rocks, in: Landslides, Proceedings of the Fifth International Symposium on Landslides, edited by Bonnard, C., Balkema, Rotterdam, 2, 1269-1272, 1988.

Zêzere, J. L.: Movimentos de vertente e perigosidade geomorfológica na Região a Norte de Lisboa (Landslides and Landslide hazard assessment in the Area North of Lisbon), PhD Thesis, University of Lisbon, 1997 (in Portuguese).

Zêzere, J. L.: Rainfall triggering of landslides in the Area North of Lisbon, edited by Bromhead, E., Dixon, N., and Ibsen, M.-L., Landslides in Research, Theory and Practice, Thomas Telford, London, 3, 1629-1634, 2000.

Zêzere, J. L.: Landslide susceptibility assessment considering landslide typology, A case study in the area north of Lisbon (Portugal), Natural Hazards and Earth System Sciences, European Geophysical Society, 2, 73-82, 2002.

Zêzere, J. L., and Rodrigues, M. L.: Rainfall Thresholds for Landsliding in Lisbon Area (Portugal), edited by Rybar, Stemberk and Wagner, Landslides, A.A. Balkema, Lisse, 333-338, 2002.

Zêzere, J. L., Ferreira, A. B., and Rodrigues, M. L.: Landslides in the North of Lisbon Region (Portugal): Conditioning and Triggering factors, Physics and Chemistry of the Earth (Part A), 24, 10, 925-934, 1999. 